\title{
Effects of a strobilurin-based spray programme on disease control, green leaf area, yield and development of fungicide-resistance in Mycosphaerella graminicola in Northern Ireland
}

\author{
C. McCartney ${ }^{a}$, P.C. Mercer ${ }^{a, b, *}$, L.R. Cooke ${ }^{a, b}$, B.A. Fraaije ${ }^{c}$ \\ ${ }^{a}$ Department of Applied Plant Science, The Queen's University of Belfast, Newforge Lane, Belfast BT9 $5 P X, U K$ \\ ${ }^{\mathrm{b}}$ Applied Plant Science Division, Agri-Food \& Biosciences Institute, Newforge Lane, Belfast BT9 5PX, UK \\ ${ }^{\mathrm{c}}$ Rothamsted Research, Harpenden, Hertfordshire AL5 2JQ, UK
}

Received 30 June 2006; received in revised form 18 October 2006; accepted 31 October 2006

\begin{abstract}
The effects of a range of strobilurin fungicides in programmes with the demethylation-inhibiting (DMI), epoxiconazole, or with chlorothalonil, were assessed in field experiments in Northern Ireland in 2004 and 2005 using the winter wheat cultivars Robigus and Savannah, partially resistant and moderately susceptible, respectively, to septoria tritici blotch. The development of strobilurin resistance was quantified using substitution of glycine by alanine in the target cytochrome $b$ as a marker (G143A). Addition of strobilurins to epoxiconazole did not significantly reduce disease, increase green leaf area (GLA) or increase yield compared with epoxiconazole alone. However, azoxystrobin alone, despite failing to control disease or increase GLA, did increase yield compared with the untreated control. A mixture of azoxystrobin and chlorothalonil gave a significantly higher yield than either azoxystrobin or chlorothalonil alone. Higher frequencies of the strobilurin resistant allele (A143) were always selected for by treatments that included a strobilurin compared with those without. Frequencies of resistance were higher at the end of 2004 than at the start and there was a further increase in 2005 . Field surveys of commercial winter wheat crops in 2004 and 2005 confirmed this trend of increasing strobilurin resistance in Mycosphaerella graminicola.
\end{abstract}

(C) 2006 Elsevier Ltd. All rights reserved.

Keywords: Fungicide; Fungicide-resistance; Strobilurin; Mycosphaerella graminicola; Winter wheat

\section{Introduction}

Septoria tritici blotch caused by Mycosphaerella graminicola (anamorph: Septoria tritici) is the most economically important foliar disease of wheat in Northern Ireland. The economic loss in the UK in 1998 was estimated to be $£ 35.5$ million (Hardwick et al., 2001). From 1980 until the late 1990s, disease control relied heavily on the demethylationinhibiting (DMI) fungicides. The introduction in 1997 of the strobilurin fungicides, which act by inhibiting the Qo site of the cytochrome $b c 1$ complex in the mitochondria (QoIs) led to the outclassing of the DMIs in control of

\footnotetext{
*Corresponding author. Department of Applied Plant Science, The Queen's University of Belfast, Newforge Lane, Belfast BT9 5PX, UK.

E-mail address: Peter.Mecer@afbini.gov.uk (P.C. Mercer).
}

septoria tritici blotch, owing to superior disease control and additional effects on the physiology of the plant (Fraaije et al., 2003).

Resistance to QoI fungicides was first detected in 1998, 2 years after their introduction, in wheat powdery mildew (Blumeria graminis f.sp. tritici) in Northern Germany (Heaney et al., 2000). In 1999, barley powdery mildew (B. graminis f.sp. hordei) also developed resistance in Northern Germany (Heaney et al., 2000). In 2002, resistance in field populations of $M$. graminicola in the UK and Ireland was reported (Fraaije et al., 2003). In both B. graminis and $M$. graminicola, resistance is associated with a point mutation in the cytochrome $b$ gene. This mutation leads to a change from glycine to alanine at the amino-acid residue 143 (Heaney et al., 2000). Initial testing of field populations of M. graminicola in Great Britain and Ireland showed low 
frequencies of resistance to the QoI fungicides (Fraaije et al., 2003). Within one season, however, this had become widespread (Fraaije et al., 2005a). As a consequence, control of M. graminicola now relies heavily on the DMIs and chlorothalonil. The QoI fungicides continue to be used in spite of this reduced efficacy against $M$. graminicola due to their positive physiological effect on the plant, possible role in resistance management strategies and effect on other wheat diseases (Clark, 2003, 2006).

Despite the importance of septoria tritici blotch in Northern Ireland wheat production, information on QoI resistance and its impact on control are lacking. Indeed, there are few published papers in scientific journals on the practical implications of QoI resistance in cereals. The aims of this study were therefore to determine the level of resistance to the QoI fungicides in $M$. graminicola populations in Northern Ireland and to investigate the use of the QoIs and DMIs alone or in mixtures in disease control and as a resistance management strategy.

\section{Materials and methods}

\subsection{Field trials}

\subsubsection{Location of field trial sites}

Field trials were carried out using commercially grown winter wheat cultivars selected from the Home-Grown Cereals Authority (HGCA) recommended list 2003/2004 on the basis of resistance to M. graminicola (1-9 scale where 9 indicates completely resistant). Trials were carried out in the 2003/2004 and 2004/2005 growing seasons using cultivars Savannah (4) and Robigus (7). All trials were sown at Hillsborough, Co. Down, Northern Ireland.

\subsubsection{Layouts and treatments}

Trials were laid out in a fully randomised block design (4 blocks $\times 9$ treatments $\times 2$ cultivars). Plot sizes were $2 \times 18 \mathrm{~m}$. Combinations of QoIs (azoxystrobin, picoxystrobin, trifloxystrobin and pyraclostrobin), a DMI (epoxiconazole) and chlorothalonil (a multi-site inhibitor) were used. Fungicide treatments were applied at the manufacturers' recommended rates (Table 1) at GS 32 (two nodes detectable) and GS 39 (flag leaf) (Table 2). Fungicides were applied with an Oxford Precision Sprayer using an application volume of $2001 \mathrm{ha}^{-1}$.

\subsubsection{Disease and green leaf area (GLA) assessments}

Ten tillers were collected at random from every plot at different dates during the season (Table 2). Mean diseased area was determined by estimating the leaf area affected by septoria tritici blotch on the top three leaves of each of the 10 tillers using the key described by James (1971). Mean diseased area on each leaf was then recorded. Mean GLA was estimated by subtraction of the diseased and senescent areas from $100 \%$. Because of seasonal variation in crop development and disease onset, data were presented from the assessments and leaf layer that gave the clearest demonstrations of treatment effects.

\subsubsection{Leaf sampling for resistance quantification}

Samples of 100 leaves were collected randomly from the untreated control plots pre-treatment in each year (GS 31), and from all plots mid-season after one fungicide application (GS 36) and after the second fungicide treatment (GS 60 in 2004, GS 77 in 2005). M. graminicola DNA was extracted and the frequency of resistance determined as described in Section 2.3.

\subsubsection{Grain yield}

Yield data were collected from each trial plot. A $1500 \mathrm{~g}$ sub-sample of grain was oven-dried $\left(80^{\circ} \mathrm{C}\right)$ and yield at $15 \%$ moisture content calculated. The dried grain was used to estimate the 1000-grain weight and the hectolitre weight.

\subsubsection{Analyses}

Analyses of variance were carried out on data from the disease, GLA and yield assessments using GenStat Release 8.2 (Lawes Agricultural Trust (Rothamsted Research Station), 2005). The analyses were performed using 9 fungicide treatments $\times 2$ cultivars, taking the fungicide treatments, cultivars and their interactions to be fixed effects and blocks as random effects. The LSDs were based on the error variances estimated from the interaction between the blocks and fungicide treatment $\times$ cultivar

Table 1

Fungicide treatments and timings for 2004-2005

\begin{tabular}{|c|c|c|c|}
\hline Proprietary name & Manufacturer & Active ingredient $\mathrm{t}^{\mathrm{a}}$ & Abbreviation \\
\hline Control & & None & ut ctrl \\
\hline Opus & BASF & Epoxiconazole & ep \\
\hline Opus + Acanto & BASF + Syngenta & Epoxiconazole + picoxystrobin & pic + ep \\
\hline Opus + Comet & BASF & Epoxiconazole + pyraclostrobin & pyr + ep \\
\hline Opus + Twist & BASF + Bayer & Epoxiconazole + trifloxystrobin & tri + ep \\
\hline Opus + Amistar & BASF + Syngenta & Epoxiconazole + azoxystrobin & $\mathrm{az}+\mathrm{ep}$ \\
\hline Amistar & Syngenta & Azoxystrobin & $\mathrm{az}$ \\
\hline Amistar + Bravo & Syngenta & Azoxystrobin + chlorothalonil & $\mathrm{az}+\mathrm{chl}$ \\
\hline Bravo & Syngenta & Chlorothalonil & chl \\
\hline
\end{tabular}

${ }^{\mathrm{a}}$ All active ingredients applied at $250 \mathrm{~g} \mathrm{ha}^{-1}$ with the exception of chlorothalonil which was $1000 \mathrm{~g} \mathrm{ha}^{-1}$; all products sprayed at GS 32 and GS 39 . 
Table 2

Dates and growth stages (in brackets) for field operations in winter wheat trials, 2003-2005

\begin{tabular}{|c|c|c|c|c|c|c|}
\hline \multirow[t]{2}{*}{ Season } & \multirow[t]{2}{*}{ Sowing date } & \multicolumn{2}{|c|}{ Fungicide sprays } & \multicolumn{2}{|c|}{ Disease assessments } & \multirow[t]{2}{*}{ Harvest date } \\
\hline & & Timing 1 & Timing 2 & No. 3 & No. 4 & \\
\hline $2003 / 2004$ & $24 / 10 / 2003$ & $27 / 4 / 2004$ & $25 / 5 / 2004$ (39) & $14 / 6 / 2004(60)$ & $28 / 6 / 2004(75)$ & $31 / 8 / 2004$ \\
\hline $2004 / 2005$ & $20 / 9 / 2004$ & $6 / 6 / 2005(32)$ & $20 / 6 / 2005$ (39) & $31 / 6 / 2005(60)$ & $18 / 7 / 2005(73)$ & $20 / 9 / 2005$ \\
\hline
\end{tabular}

combinations. Angular transformation of means of all percentage data was carried out to improve normality, with the one exception of resistance quantification of the resistant A143 allele, where transformation did not improve normality and untransformed percentages are therefore shown.

\subsection{Field survey}

Farms growing winter wheat were selected randomly across N. Ireland for sampling. The farms selected were stratified by size and location. Samples of 100 leaves were collected randomly from each field before and after fungicide treatment. Leaves were air-dried and stored until required for isolation. Sensitivities of $M$. graminicola to azoxystrobin were assessed by quantitative PCR of infected leaf tissue.

\subsection{Quantification of strobilurin resistance using G143A as a marker}

\subsubsection{Isolation and quantification of $M$. graminicola $D N A$}

From each trial plot or surveyed field, 10 random leaves were placed in a leaf crusher (Sew-Eurodrive Leaf Juice Press, USA). Extraction buffer containing $40 \mu \mathrm{l} \quad 1 \% \quad(\mathrm{v} / \mathrm{v})$ $\beta$-mercapthoethanol, $400 \mu \mathrm{l}$ TEN buffer $\left(500 \mathrm{mmol}^{-1} \mathrm{NaCl}\right.$, $400 \mathrm{mmol}^{-1}$ Tris-HCL, $50 \mathrm{mmol} 1^{-1}$ EDTA, $\mathrm{pH} 8.0$ ) and $400 \mu \mathrm{l} 2 \%$ (w/v) SDS was filtered through the material and DNA further extracted as described by Fraaije et al. (1999).

The DNA was quantified using a FLX 800 microplate fluorescence reader (Bio-Tec Instruments Inc. Winooski, USA) in flat bottom black 96-well microtitre plates (Thermo Life Sciences, Basingstoke, UK) using the fluorescent dye, thiazole orange $(2 \mu \mathrm{M})$ (Aldrich Chemical Co., Milwaukee, USA). The fluorescence was measured at $530 \mathrm{~nm}$ with excitation at $480 \mathrm{~nm}$. For real-time PCR, a total of $50 \mathrm{ng}$ of DNA was used in the reaction (Fraaije et al., 2005b).

\subsubsection{Allele specific real-time $P C R$}

To detect strobilurin-resistant A143 (R) alleles in DNA samples, a real-time PCR assay using two primers and three minor groove binder-conjugated TaqMan probes was used, as described recently by Fraaije et al. (2005b). According to this assay, the signal of the CY5-conjugated probe indicates the total amount of cytochrome $b$ alleles. The ratio of the FAM and VIC signals, corresponding to G143 (S) and A143 (R) alleles, respectively, was measured
5 cycles after detection of the CY5 probe, and used to calculate $\mathrm{R}$-allele frequencies. This was done by reference to a calibration curve generated by DNA standards containing different proportions of $\mathrm{R}$ - and S-alleles.

\section{Results}

\subsection{Field trials}

\subsubsection{Effect of fungicide treatment on disease levels and GLA}

The levels of infection and GLA were compared in the two winter wheat field trials at GS 60 and GS 73-75. The resistant cv. Robigus had less disease and greater GLA than the susceptible Savannah and the effect of cultivar was significant at some assessments (Table 3), but there was no interaction between fungicide and cultivar in any case, so the fungicide results are presented meaned over cultivar.

At GS 60 (Fig. 1a), there was a very highly significant effect of fungicide treatment in both years $(P<0.001)$. In 2004, epoxiconazole alone proved effective in reducing disease compared with the untreated plots, but adding a strobilurin did not significantly improve control. Similarly, plots treated with an azoxystrobin/chlorothalonil mixture did not have significantly lower levels of disease than those treated with chlorothalonil alone. In 2005, the level of disease at this growth stage was low and no treatment significantly reduced disease compared with the untreated control.

At GS 73-75 in both years (Fig. 1b), there was less disease with epoxiconazole alone than with the untreated control and this difference was significant in 2005. The levels of disease in plots treated with a strobilurin plus epoxiconazole were generally greater than in those treated with epoxiconazole alone. Plots treated with azoxystrobin alone were the most severely infected apart from the untreated controls, but, surprisingly, in 2005 , there was a highly significant reduction of infection in plots treated with the azoxystrobin/chlorothalonil mixture compared with those treated with chlorothalonil alone.

Analysis of GLA for leaf 3 at GS 60 in 2004 (Fig. 2a) showed a general increase with fungicide treatments compared with the untreated control, although azoxystrobin alone performed least well; there was no significant effect at this growth stage in 2005. At GS 73-75 (Fig. 2b), plots receiving azoxystrobin alone did not differ significantly from the untreated control in 2004, but in 2005 had a significantly lower GLA than the untreated plots. 
Table 3

Effect of cultivar on septoria tritici blotch, green leaf area and yield in winter wheat trials in 2004 and 2005

\begin{tabular}{|c|c|c|c|c|c|c|c|c|}
\hline \multirow[t]{2}{*}{ Assessment } & \multicolumn{4}{|l|}{2004} & \multicolumn{4}{|l|}{2005} \\
\hline & Robigus & Savannah & $\operatorname{LSD}(P<0.05)$ & Significance & Robigus & Savannah & $\operatorname{LSD}(P<0.05)$ & Significance \\
\hline \multicolumn{9}{|l|}{ Septoria $^{\mathrm{a}}$} \\
\hline GS60 & 5.9 & 16.4 & 1.09 & $<0.001$ & 2.7 & 3.7 & 1.25 & 0.116 \\
\hline GS73-75 & 23.9 & 29.2 & 7.01 & 0.137 & 15.02 & 13.14 & 1.71 & 0.221 \\
\hline \multicolumn{9}{|l|}{$G L A^{\mathrm{b}}$} \\
\hline GS60 & 68.0 & 59.9 & 2.23 & $<0.001$ & 82.7 & 80.7 & 1.74 & 0.029 \\
\hline GS73-75 & 50.1 & 41.7 & 4.31 & 0.058 & 64.8 & 75.0 & 4.35 & $<0.001$ \\
\hline \multicolumn{9}{|l|}{ Yield } \\
\hline Yield $\left(\mathrm{t} \mathrm{ha}^{-1}\right)$ & 8.8 & 7.6 & 0.57 & $<0.001$ & 4.4 & 3.4 & 0.50 & $<0.001$ \\
\hline Thousand-grain weight (g) & 34.0 & 37.2 & 1.16 & $<0.001$ & 41.2 & 48.6 & 1.31 & $<0.001$ \\
\hline Hectolitre weight (g) & 68.6 & 67.6 & 0.81 & 0.017 & 72.3 & 73.3 & 0.53 & $<0.001$ \\
\hline
\end{tabular}

${ }^{a}$ Percentage (angular transformed) septoria tritici blotch on leaf 3.

${ }^{\mathrm{b}}$ Percentage (angular transformed) green leaf area for leaf 3.
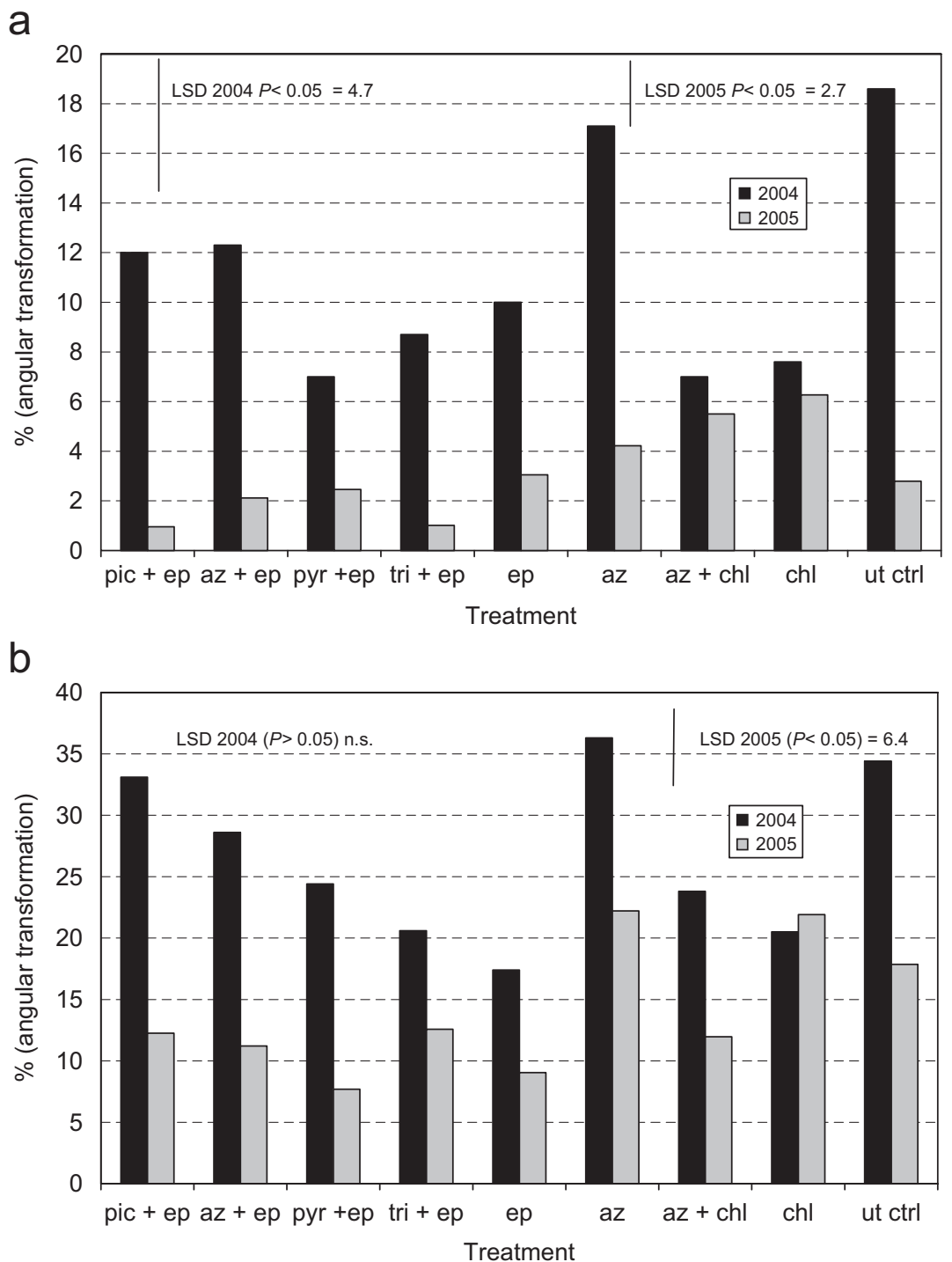

Fig. 1. Effect of fungicide programmes on \% (angular transformation) area of septoria tritici blotch on leaf 3 at (a) GS 60 , (b) GS $73-75$ in 2004 and 2005 in winter wheat trials (treatment abbreviations in Table 1). 
a

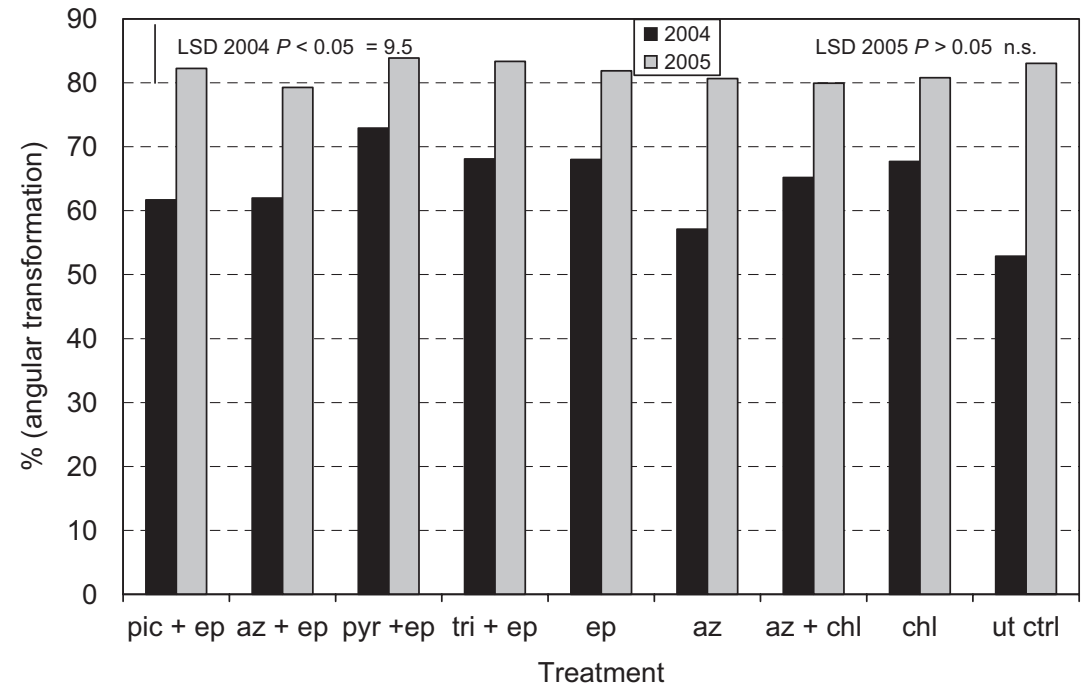

b

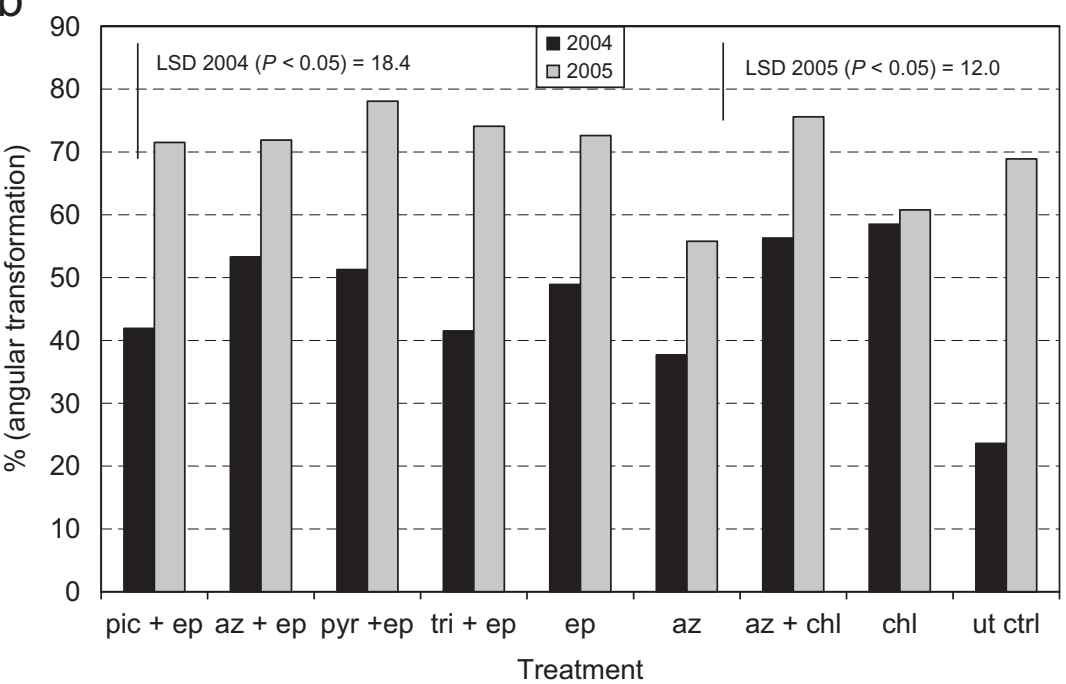

Fig. 2. Effect of fungicide programmes on \% (angular transformation) green leaf area of leaf 3 at (a) GS 60, (b) GS 73-75 in 2004 and 2005 in winter wheat trials (treatment abbreviations in Table 1).

Addition of a strobilurin to epoxiconazole did not significantly increase the GLA compared with epoxiconazole alone in either year, but addition of azoxystrobin to chlorothalonil did increase the GLA compared with chlorothalonil alone in 2005.

\subsubsection{Effects of fungicide treatments on yield}

The resistant cv. Robigus had a greater yield, but a lower 1000-grain weight than the susceptible Savannah (Table 3), but there was no interaction between fungicide and cultivar, so fungicide results are again meaned over cultivar. In 2004, only pyraclostrobin/epoxiconazole, trifloxystrobin/epoxiconazole and azoxystrobin/chlorothalonil increased yield significantly compared with the untreated control (Fig. 3). Plots treated with pyraclostrobin/epoxiconazole also had a significantly greater yield than those receiving epoxiconazole alone, while plots treated with azoxystrobin/chlorothalonil had a significantly greater yield than those treated with chlorothalonil alone. In 2005, despite the lower level of disease and greater GLA, yields were considerably less than in 2004, probably because of late sowing and poor growing conditions, and there was no significant effect of treatment.

Treatment significantly affected 1000-grain weights (Fig. 4) and hectolitre weights (data not presented) only in $2004(P<0.001)$. There was no significant difference between the thousand-grain weights of those plots treated with any strobilurin/epoxiconazole mixture and those treated with epoxiconazole alone. However, those plots treated with the strobilurin/chlorothalonil mixture had a significantly greater thousand-grain weight than those receiving chlorothalonil alone. 


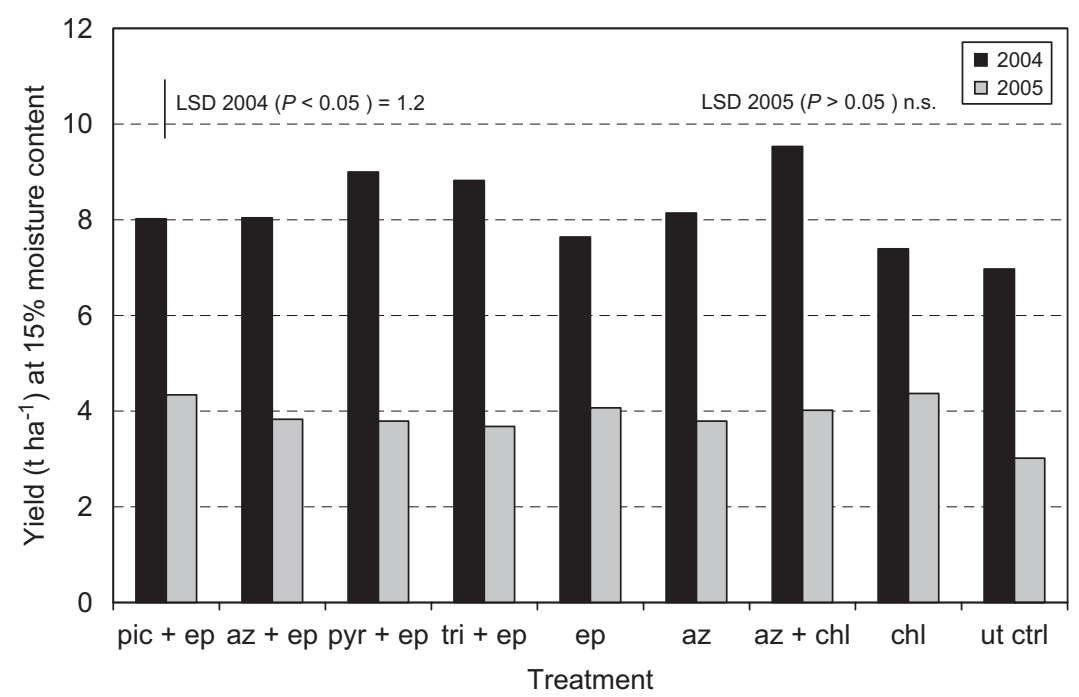

Fig. 3. Effect of fungicide programmes on yield of winter wheat, in field trials in 2004 and 2005 (treatment abbreviations in Table 1).

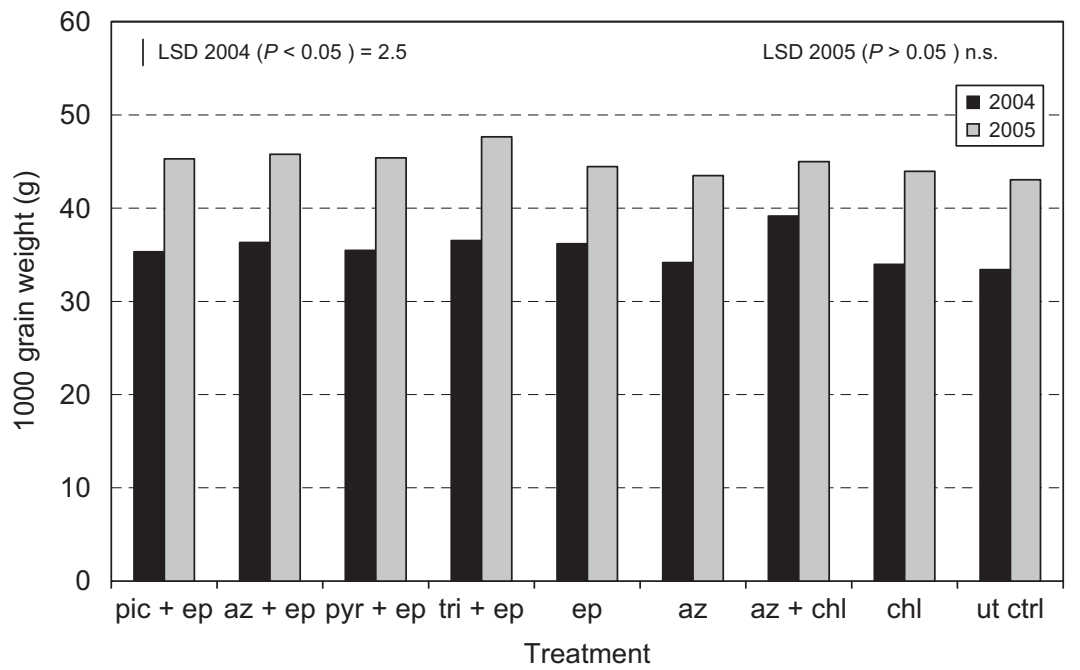

Fig. 4. Effect of fungicide programmes on thousand-grain weight of winter wheat, in field trials in 2004 and 2005 (treatment abbreviations in Table 1).

\subsubsection{Effects of fungicide treatments on frequencies of QoI resistance}

The level of G143A resistance was quantified for each of the 2 years (Fig. 5); results are meaned over cultivar as there was no significant cultivar effect. In 2004, results are shown from pre-season samples and after one and two fungicide sprays (Fig. 5). In 2005, results after one spray were omitted as the level of resistance was very high throughout the trial. In 2004, the analysis of resistance frequencies showed a highly significant effect of treatment after both one and two sprays $(P<0.001)$ and frequencies were higher than in the pre-season samples except after two sprays of chlorothalonil alone. After one fungicide spray, the only treatments that had significantly higher frequencies of resistance than the untreated control were the pyraclostrobin/epoxiconazole and picoxystrobin/epoxiconazole mixtures. However, plots treated with epoxicona- zole alone had a significantly lower level of resistance than any plot treated with an epoxiconazole/strobilurin mixture.

After two fungicide sprays, plots treated with chlorothalonil alone had a significantly lower level of resistance than either the untreated control or plots treated with the azoxystrobin/chlorothalonil mixture $(P<0.001)$. None of the treatments had significantly higher frequencies of resistance than the untreated control, but all plots receiving treatments containing strobilurins had higher frequencies of resistance than those, which were not strobilurin treated.

In 2005, the level of resistance was higher than in 2004 even in the pre-treatment samples, where it was $89 \%$. The frequencies of resistance had increased further by the end of the 2005 season being over $90 \%$ in all treatments. Only the azoxystrobin alone and the pyraclostrobin/epoxiconazole treatments had significantly higher frequencies of resistance than the untreated control. 
a

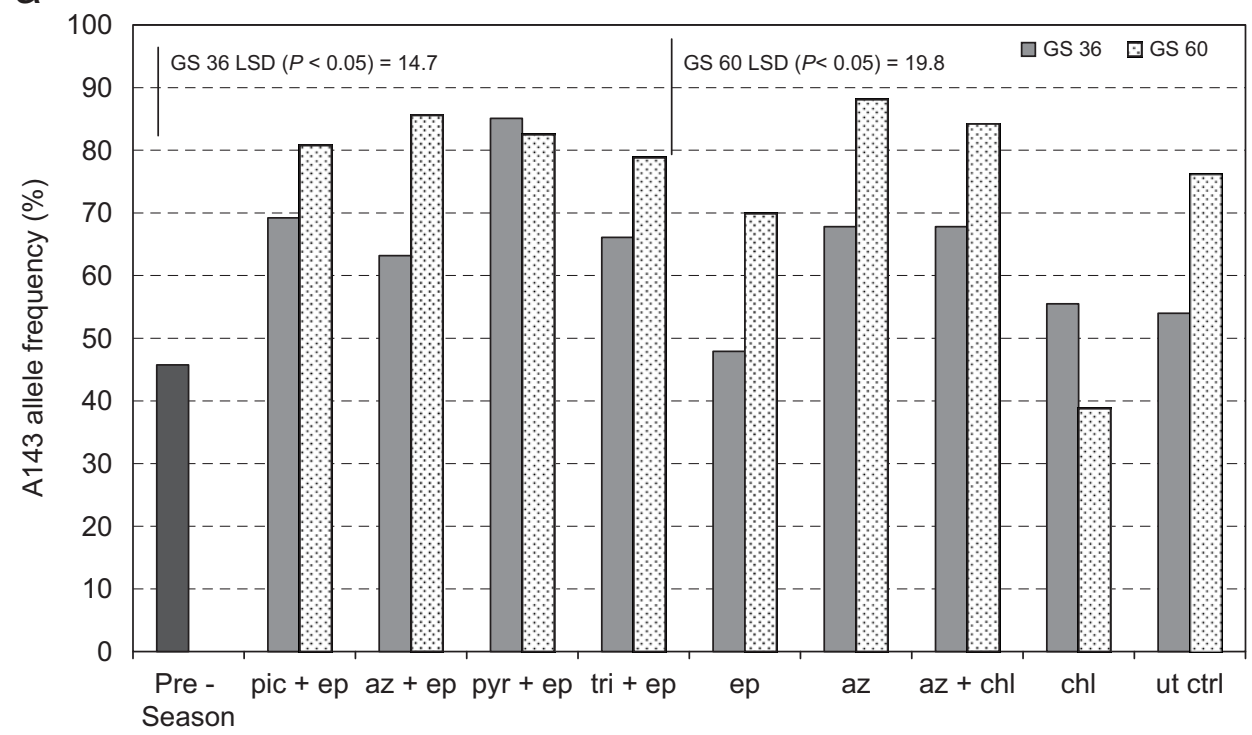

Treatment

b

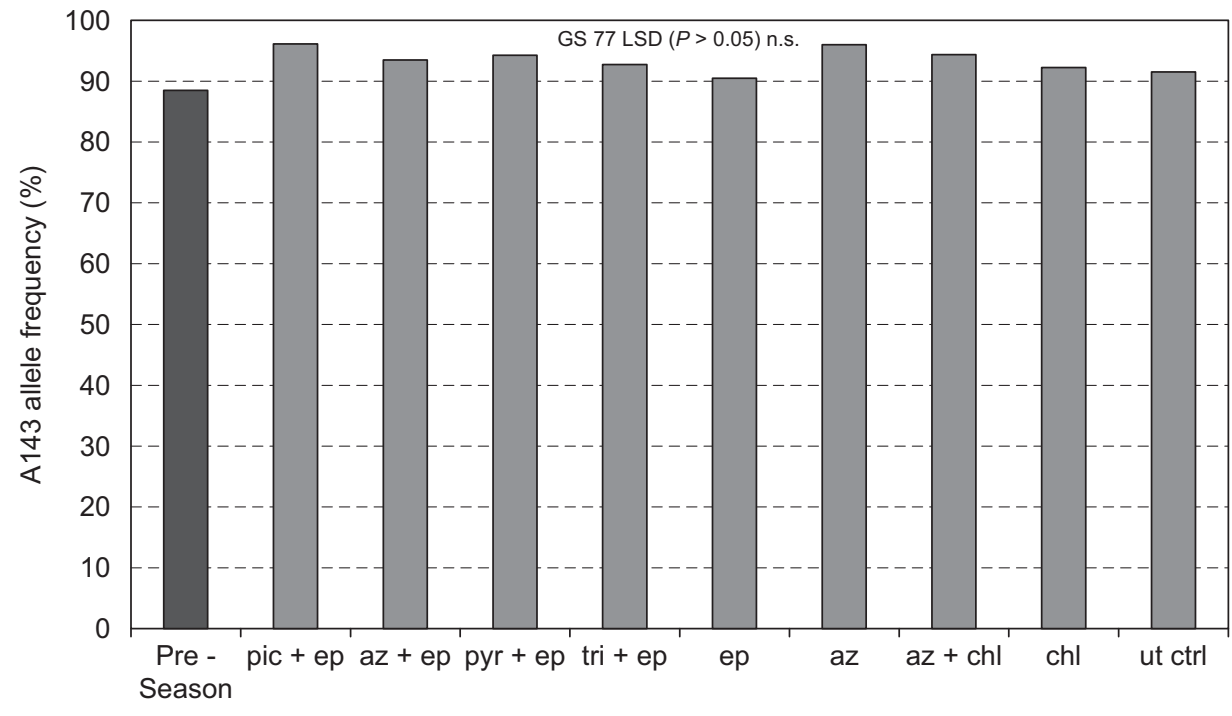

Treatment

Fig. 5. Effect of fungicide programmes on frequencies of strobilurin-resistance in Mycosphaerella graminicola in winter wheat trials in (a) 2004 and (b) 2005 (treatment abbreviations in Table 1).

\subsection{Field surveys}

The G143A mutation, which confers resistance to strobilurin fungicides, proved to be common and widespread in populations of $M$. graminicola throughout Northern Ireland during the 2004 and 2005 growing seasons (Tables 4 and 5). The frequencies of the mutation increased after fungicide application in 2004. They also apparently increased over the 2 years with pre-treatment frequencies in 2005 being considerably higher than pretreatment in 2004 and similar to the frequencies at the end of 2004. There was no association between cultivar and frequencies of resistance, nor was there any marked effect of location.

\section{Discussion}

The economic damage caused by $M$. graminicola in Northern Ireland every year makes it necessary to develop an effective and sustainable method of control. Current control methods make use of mixtures of fungicides with different modes of action, including the strobilurins and the DMIs. In the wake of resistance to the strobilurins, the validity of using this approach has been questioned. However, this group of fungicides continues to be used extensively due to their perceived positive physiological effect on the plant (Ruske et al., 2003).

In the present study, two winter wheat trials compared the effect of single products and mixtures to ascertain if 
Table 4

Distribution of R-allele frequency (\%) in winter wheat fields sampled across Northern Ireland in 2004 (ordered alphabetically by county and cultivar)

\begin{tabular}{llcc}
\hline Location & Cultivar & $\begin{array}{l}\text { Pre-treatment } \\
\text { \% R-allele }\end{array}$ & $\begin{array}{c}\text { Post-treatment } \\
\text { \% R-allele }\end{array}$ \\
\hline Co. Antrim & Claire & 56 & 70 \\
Co. Antrim & Claire & 18 & 22 \\
Co. Armagh & Claire & 60 & 94 \\
Co. Armagh & Consort & 70 & 78 \\
Co. Antrim & Savannah & 15 & 78 \\
Co. Down & Claire & 64 & 100 \\
Co. Down & Claire & 71 & 55 \\
Co. Down & Consort & 70 & 74 \\
Co. Down & Consort & 45 & 100 \\
Co. Down & Consort & 51 & 77 \\
Co. Down & Consort & 88 & 87 \\
Co. Down & Einstein & 27 & 50 \\
Co. Down & Einstein & 65 & 100 \\
Co. Down & Napier & 30 & 6 \\
Co. Down & Napier & 4 & 85 \\
Co. Down & Napier & 69 & 88 \\
Co. Down & Napier & 16 & 60 \\
Co. Down & Richmond & 79 & 90 \\
Co. Down & Tanker & 100 & 100 \\
Co. Londonderry & Access & 90 & 100 \\
Co. Londonderry & Claire & 100 & 100 \\
\hline
\end{tabular}

${ }^{\text {a } C o n s o r t, ~ S a v a n n a h ~ a n d ~ T a n k e r ~ h a v e ~ a n ~ H G C A ~(s e p t o r i a ~ t r i t i c i ~ b l o t c h) ~}$ resistance rating of 4 . Einstein, Napier and Richmond have a resistance rating of 5. Claire has a resistance rating of 6 .

Table 5

Distribution of R-allele frequency (\%) in winter wheat fields sampled across Northern Ireland in 2005 (ordered alphabetically by county and cultivar

\begin{tabular}{llcc}
\hline Location & Cultivar $^{\mathrm{a}}$ & $\begin{array}{l}\text { Pre-treatment } \\
\% \text { R-allele }\end{array}$ & $\begin{array}{l}\text { Post-treatment } \\
\% \text { R-allele }\end{array}$ \\
\hline Co. Armagh & Consort & 71 & 100 \\
Co. Armagh & Consort & 100 & 89 \\
Co. Armagh & Napier & 100 & 72 \\
Co. Down & Claire & 69 & 95 \\
Co. Down & Claire & 83 & 99 \\
Co. Down & Robigus & 80 & 83 \\
Co. Londonderry & Claire & 100 & 100 \\
\hline
\end{tabular}

${ }^{a}$ Consort has an HGCA (septoria tritici blotch) resistance rating of 4 , Napier has a resistance rating of 5, Claire has a resistance rating of 6 and Robigus has a resistance rating of 7 .

strobilurin fungicides continue to be effective in maintaining GLA and increasing yields (Ruske et al., 2003). Generally, using azoxystrobin alone or a strobilurin in a mixture did not significantly lower disease levels or maintain GLA. This contrasts with work by Maury and Planchon (reported by Clark (2003)) on the strobilurins, trifloxystrobin, azoxystrobin and kresoxim-methyl, under glasshouse conditions in the absence of disease. All the strobilurin treatments increased GLA of the flag leaf by $20 \%$ compared with an untreated control and this was correlated with increased nitrate reductase and decreased transpiration, but only in the case of trifloxystrobin. Prior to the onset of fungicide-resistance by $M$. graminicola in the late 1990s, strobilurins were much more effective in controlling disease and increasing yield than the DMIs (Jørgensen and Nielsen, 1998). Following widespread fungicide-resistance in M. graminicola, Clark (2006) reported that greening effects of strobilurin fungicides on wheat crop canopies still occurred, but indicated that the earlier, large yield responses could no longer be relied upon. Results from the present work indicate that in 2004, despite relatively poor performance in terms of disease control and GLA, using a strobilurin in a mixture with the DMI epoxiconazole generally resulted in a higher yield than the untreated control, whereas epoxiconazole alone did not. Indeed, the mixture of pyraclostrobin and epoxiconazole gave a significantly higher yield than epoxiconazole alone. Surprisingly, in that year, even applying azoxystrobin alone, which was the poorest treatment in controlling disease, increased the yield and adding azoxystrobin to chlorothalonil also improved yield compared with chlorothalonil alone. The reasons for the beneficial effects of applying strobilurins in 2004 are unclear. In 2005, mixtures of strobilurins and epoxiconazole were not significantly different from epoxiconazole alone in disease control, GLA or yield, but this was against a background of relatively poor crop growth and higher fungicide resistance than in 2004.

The results from the surveys of commercial crops indicate that in Northern Ireland the level of the G143A mutation for resistance increased within and between the 2004 and 2005 seasons and was approaching $100 \%$ by the end of 2005. The same trend of seasonal change took place in the rest of the UK and in the Republic of Ireland (Fraaije et al., 2005a). In the field trials, treatments including strobilurins resulted in higher frequencies of G143A than those lacking strobilurins. The intensive use of strobilurins leads to direct competition of the resistant population and the wild type population (Gisi et al., 2002) and, since the high level resistance associated with the point mutation G143A does not have any apparent fitness penalty (Fraaije et al., 2003), there is strong selection for this mutation. In those plots where epoxiconazole alone or chlorothalonil alone was applied, the frequencies of resistance were similar to those in the untreated plots. The poorer performance of strobilurins in the 2005 field trial is probably related to the much higher average starting level of G143A resistance in this season (80\%) compared with 2004 average $(40 \%)$, although the lower incidence of disease in 2005 complicates the comparison.

From these trials, it is clear that the strobilurins are not controlling septoria tritici blotch in winter wheat in Northern Ireland. In the light of the high frequencies of resistance, and with the lack of a clear beneficial physiological effect on the plant, the use of the strobilurins in the field in Northern Ireland has to be questioned. Moreover, using strobilurins with DMI fungicides can no longer be considered to provide a useful resistance 
management strategy to reduce selection for DMI resistance. However, even in the presence of high levels of disease, the strobilurins increased yield. The mechanism of this yield increase has not been established and it is debatable whether the beneficial yield effect can be maintained and is sufficient to give an economic benefit in Northern Ireland.

\section{Acknowledgements}

We gratefully acknowledge the Department of Education and Learning (DEL) in Northern Ireland for funding the postgraduate research of C. McCartney. We thank the farmers in Northern Ireland who kindly permitted access to their land for the survey and A. Ruddock and F. Andrews for their assistance in the field trials and surveys.

\section{References}

Clark, D.C., 2003. Agronomic implications of some morphological and biochemical effects of trifloxystrobin in wheat growing. Pflanzenschutz-Nachr. Bayer 56, 281-296.

Clark, W.S., 2006. Foliar disease management strategies in cereals: current challenges. In: Proceedings of Home-Grown Cereals Authority Conference (Arable Crop Protection in the Balance: Profit and the Environment), 25-26 January 2006, Grantham, Lincolnshire, UK, Paper 7.1.

Fraaije, B.A., Lovell, D.J., Rohel, E.A., Hollomon, D.W., 1999. Rapid detection and diagnosis of Septoria tritici epidemics in wheat using a polymerase chain reaction/PicoGreen assay. J. Appl. Microbiol. 86, 701-708.

Fraaije, B.A., Lucas, J.A., Clark, W.S., Burnett, F.J., 2003. QoI resistance development in populations of cereal pathogens in the UK. In: The BCPC International Congress - Crop Science \& Technology, pp. 689-694.

Fraaije, B.A., Burnett, F.J., Clark, W.S., Motteram, J., Lucas, J.A., 2005a. Resistance development to QoI inhibitors in populations of Mycosphaerella graminicola in the UK. In: Modern Fungicides and Antifungal Compounds IV, BCPC, vol. 8, pp. 63-71.

Fraaije, B.A., Cools, H.J., Fountaine, J., Lovell, D.J., Motteram, J., West, J.S., Lucas, J.A., 2005b. Role of ascospores in further spread of QoIResistant cytochrome $b$ alleles (G143A) in field populations of Mycosphaerella graminicola. Phytopathology 95, 933-941.

Gisi, U., Sierotzki, H., Cook, A., McCaffery, A., 2002. Mechanisms influencing the evolution of resistance to Qo inhibitor fungicides. Pest Manage. Sci. 58, 859-867.

Hardwick, N.V., Jones, D.R., Slough, J.E., 2001. Factors affecting diseases in winter wheat in England and Wales, 1989-98. Plant Pathol. $50,453-462$.

Heaney, S.P., Hall, A.A., Davies, S.A., Olaya, G., 2000. Resistance to fungicides in the QoI-STAR cross-resistance group: current perspectives. In: The BCPC Conference-Pests \& Diseases 2000, pp. 755-762.

James, W.C., 1971. An illustrated series of assessment keys for plant disease, their preparation and usage. Can. Plant Dis. Surv. 51, 39-65.

Jørgensen, L.N., Nielsen, G.C., 1998. Reduced doses of strobilurins for disease management in winter wheat. In: British Crop Protection Conference-Pests and Diseases, pp. 993-998.

Ruske, R.E., Gooding, M.J., Jones, S.A., 2003. The effects of adding picoxystrobin, azoxystrobin and nitrogen to a triazole programme on disease control, flag leaf senescence, yield and grain quality winter wheat. Crop Prot. 22, 975-987. 